\title{
Neurofibromin Modulates Adult Hippocampal Neurogenesis and Behavioral Effects of Antidepressants
}

\author{
Yun Li, ${ }^{1}$ Yanjiao Li, ${ }^{1}$ Renée M. McKay, ${ }^{1}$ Dieter Riethmacher, ${ }^{2}$ and Luis F. Parada ${ }^{1}$ \\ ${ }^{1}$ Department of Developmental Biology and Kent Waldrep Center for Basic Research on Nerve Growth and Regeneration, University of Texas Southwestern \\ Medical Center, Dallas, Texas 75390-9133, and 2Development and Regeneration, Human Genetics Division, University of Southampton, Southampton, \\ United Kingdom
}

Neurogenesis persists in the rodent dentate gyrus (DG) throughout adulthood but declines with age and stress. Neural progenitor cells (NPCs) residing in the subgranular zone of the DG are regulated by an array of growth factors and respond to the microenvironment, adjusting their proliferation level to determine the rate of neurogenesis. Here we report that genetic deletion of neurofibromin ( $\mathrm{Nf1}$ ), a tumor suppressor with RAS-GAP activity, in adult NPCs enhanced DG proliferation and increased generation of new neurons in mice. Nf1 loss-associated neurogenesis had the functional effect of enhancing behavioral responses to subchronic antidepressants and, over time, led to spontaneous antidepressive-like behaviors. Thus, our findings establish an important role for the Nf1-Ras pathway in regulating adult hippocampal neurogenesis, and demonstrate that activation of adult NPCs is sufficient to modulate depression- and anxiety-like behaviors.

\section{Introduction}

The continuous production of new neurons by neural progenitor cells (NPCs) in the adult dentate gyrus (DG) is an intricate process influenced by many innate and environmental factors. While events such as aging, stress and inflammation have been shown to impair neurogenesis (Czéh et al., 2001; Monje et al., 2003; Stranahan et al., 2006), activities considered physiologically or psychologically beneficial such as learning, exploration of novel environment, and exercise, are associated with enhanced neurogenesis (Kempermann et al., 1997). Additionally, antidepressive stimulants such as electroconvulsive shock and chemical antidepressants increase adult DG neurogenesis (Malberg et al., 2000; Scott et al., 2000). This increase correlates with the expression of growth factors such as BDNF, neurotrophin-3, and VEGF (Nibuya et al., 1995; Warner-Schmidt and Duman, 2007). Adultborn granule neurons form new neural circuits within the existing structural confines of the DG. Thus, changes in neurogenesis in response to these various influences lead to anatomical modifications that may serve as a mechanism to exert control on be-

\footnotetext{
Received July 7, 2011; revised Jan. 11, 2012; accepted Jan. 12, 2012.

Author contributions: Yun Li and L.F.P. designed research; Yun Li and Yanjiao Li performed research; D.R. contributed unpublished reagents/analytic tools; Yun Li, R.M.M., and L.F.P. analyzed data; Yun Li, R.M.M., and L.F.P. wrote the paper.

This work was supported by NINDS Grant R37NS033199 and NIMH Conte Center Grant P50MH66172. L.F.P. is an American Cancer Society Research Professor. We thank Shawna Kennedy, Linda McClellan, Steven McKinnon, Andrew Tyler, and Alvin Chandra for technical support, Drs. Jian Chen and Chang-Hyuk Kwon for assistance with the Nestin-CreER ${ }^{T 2}$ mice, and members of the Parada laboratory for helpful suggestions. We thank Dr. Steven Kernie for insightful discussions.

The authors declare no competing financial interests.

Correspondence should be addressed to either Dr. Luis F. Parada, University of Texas Southwestern Medical Center, 5323 Harry Hines Boulevard, Dallas, TX 75390-9133, E-mail: luis.parada@utsouthwestern.edu, or Dr. Yun Li, at her present address: Whitehead Institute for Biomedical Research, 9 Cambridge Center, Cambridge, MA 02142, E-mail:yli@wi.mit.edu.

DOI:10.1523/JNEUROSCI.3469-11.2012

Copyright $\odot 2012$ the authors $\quad 0270-6474 / 12 / 323529-11 \$ 15.00 / 0$
}

havior. Indeed, recent studies have shown that genetic or pharmacological depletion of NPCs leads to deficits in certain aspects of learning and memory (Saxe et al., 2006; Imayoshi et al., 2008; Zhang et al., 2008). In addition, ablation of DG NPCs by irradiation or genetic deletion of the $\mathrm{BDNF}$ receptor tyrosine kinase (RTK) TrkB from NPCs is sufficient to block the behavioral effects of chronic antidepressants (Santarelli et al., 2003; Airan et al., 2007; Li et al., 2008; Wang et al., 2008). However, inhibiting neurogenesis did not result in detectable alteration in spontaneous, base level depression- and anxiety-like behavior. Thus, these loss-of-function studies highlighted the importance of adult NPCs in the effects of therapeutic agents, but did not address their physiological functions in regulating affective behaviors.

The Nf1 tumor suppressor gene encodes the protein Neurofibromin, and is a negative regulator of Ras that when mutated in human causes defects in neural development, tumorigenesis, and cognitive disorders (Gutmann and Collins, 1993). Ras signaling lies downstream of neurotrophins and Trk family RTKs to regulate neuronal survival and differentiation, and also lies downstream of other growth factors, such as VEGF, that are known to increase neurogenesis (Vogel et al., 1995). Interestingly, recent studies indicate that Nf1 participates in the regulation of GABA release, LTP and spatial learning in the hippocampus (Cui et al., 2008). Furthermore, Nf1 has been shown to regulate neuroglial progenitor proliferation and differentiation during development in a region-specific manner (Dasgupta and Gutmann, 2005; Hegedus et al., 2007; Lee et al., 2010). However, the role of Nf1 in adult DG neurogenesis has not been investigated.

In the present study, we examined the effect of $N f 1$ gene deletion on adult NPC proliferation and differentiation using a tamoxifen-inducible Nestin-CreER ${ }^{T 2}$ line (Li et al., 2008; Chen et al., 2009) that targets the majority of NPCs. We found that Nf1 
deletion in adult NPCs induced cell-autonomous activation of the ERK pathway, increased adult hippocampal neurogenesis, enhanced kinetics of antidepressant responses, and ultimately led to antidepressive-like behaviors.

\section{Materials and Methods}

Mice. R26:lacZbpA $A^{\text {flox }} D T A$, Nestin-CreER $R^{T 2}$ and $N f 1^{\text {flox }}$ mouse lines were generated as previously described (Zhu et al., 2001; Brockschnieder et al., 2006; Chen et al., 2009). R26 mice were from Jackson Laboratory. $\mathrm{Nf1} 1^{\text {flox/flox }}$; cre/wt mice were initially derived from interbreeding of $N f 1^{f l o x / w t}$ ;cre/wt mice and $N f 1^{\text {flox/flox }}$ mice. $N f 1^{\text {flox/flox }}$; $c r e / w t$ mice were subsequently generated by interbreeding $N f 1^{\text {flox/flox }} ;$ cre/wt mice and $N f 1^{\text {flox/flox }}$ mice. $D T A^{\text {flox/wt }}$; $c r e / w t$ mice were first generated by crossing $D T A^{\text {flox/wt }}$ mice with cre/wt mice, and $R 26^{\text {flox/wt }}$; cre/wt mice were generated by crossing $R 26^{f l o x / w t}$ mice with cre/wt mice. All animals were maintained on $129 / \mathrm{SvEv}$ and C57BL/6 mixed background. Tamoxifen (Sigma) was dissolved in sunflower oil at $20 \mathrm{mg} / \mathrm{ml}$. Vehicle (sunflower oil) or tamoxifen was delivered to 8 -week-old mice by gavage at $500 \mu \mathrm{l} / 20 \mathrm{~g}(500 \mathrm{mg} / \mathrm{kg})$ a day for 2 consecutive days. $N f^{\text {flox/flox }}$; cre/wt mice treated with vehicle, and $N f 1^{\text {flox/flox }}$ mice treated with tamoxifen were indistinguishable and therefore pooled as the control group. A similar strategy was used to compile the control group for DTA ${ }^{\text {Nestin }}$ mice. For BrdU incorporation assay, tissues were collected $2 \mathrm{~h}$ or $28 \mathrm{~d}$ after intraperitoneal injections (200 $\mu \mathrm{g} / \mathrm{g}$, single injection, or 5 injections with $2 \mathrm{~h}$ intervals). All mouse procedures used in this study were performed in accordance with protocols approved by the Institutional Animal Care and Research Advisory Committee at University of Texas Southwestern Medical Center.

Histology. Adult mice were intracardially perfused with $4 \%$ (w/v) PFA in PBS, and the dissected brains postfixed in $2 \%$ or $4 \%$ PFA at $4^{\circ}$. Vibratome sections ( $50 \mu \mathrm{m}$ thick) and $5 \mu \mathrm{m}$ paraffin sections were used for X-Gal staining and Nissl staining, respectively (Lush et al., 2008). X-Galstained sections were counterstained with nuclear fast red. For immunohistochemistry and immunocytochemistry, the following antibodies were used: BrdU (BD Biosciences), $\beta$-Gal (MP Biomedicals), doublecortin (Dcx; Santa Cruz Biotechnology), GFAP (DAKO, Abcam and BD Biosciences), Ki67 (NeoMarker), MBP (Covance), Nestin (BD Biosciences), NeuN (Millipore Bioscience Research Reagents), NeuroD (Santa Cruz Biotechnology), S100 (DAKO), phospho-CREB (Santa Cruz Biotechnology), phospho-ERK and phospho-AKT (Cell Signaling Technology). Primary antibodies were visualized by secondary antibodies conjugated with Cy2, Cy3 or Cy5 (Jackson ImmunoResearch) followed by counterstaining with DAPI (Vector Labs). Alternatively, sections were incubated with biotin-conjugated secondary antibodies (Vector Labs) and developed using the $\mathrm{ABC}$ kit (Vector Labs) and DAB substrate.

NPC culture. Monolayer culture of dentate gyrus-derived NPCs was established as described previously (Babu et al., 2007). Briefly, the dentate gyrus was micro-dissected from coronal slices of fresh brain tissue, and digested in $0.1 \%$ trypsin-EDTA (Sigma) followed by mechanical trituration until smooth. Cells were plated on poly-D-lysine and laminin-coated surface in complete growth medium, consisting of mouse NeuroCult NSC basal medium, mouse NeuroCult NSC proliferation supplements (StemCell Technologies), $2 \mu \mathrm{g} / \mathrm{ml}$ heparin (Sigma), $20 \mathrm{ng} / \mathrm{ml} \mathrm{EGF} \mathrm{(Invitrogen)} \mathrm{and} 10 \mathrm{ng} / \mathrm{ml}$ bFGF (Sigma). Cells were fed every $2 \mathrm{~d}$ and passaged every $8-10 \mathrm{~d}$. Recombination of the flox allele was confirmed by PCR (primers: aatgtgaaattggtgtcgagtaaggtaaccac, ttaagagcatctgctgctcttagagggaa, tcagactgattgttgtacctgatggttgtacc).

Quantitative analysis. Quantification of the total number of Ki67- and Dcx-positive cells was performed on $50-\mu \mathrm{m}$-thick sections (one in every six) through the hippocampus of one hemisphere. Confocal images of the granular layer and subgranular zone (SGZ) were taken using a Zeiss LSM-510 microscope, examined using the MetaMorph software, from which the total number was calculated. Quantification of the number of $\mathrm{X}$-Gal-positive cells was performed on $50-\mu \mathrm{m}$-thick, randomly selected sections throughout the hippocampus ( $4-6$ sections per animal). The proportion of $\beta$-Gal and NeuN double-positive cells in all neurons was assessed on $5 \mu \mathrm{m}$ sections (one in every 10) through the hippocampus. Subregions of the granular layer and SGZ from both the dorsal and ventral blades were selected, and 460-850 NeuN-positive cells were examined for each mouse ( $n=4-6$ for each genotype and age). The loca- tion of $\beta$-Gal and NeuN double-positive cells was measured in 8-monthold mice, by first dividing the granular layer (NeuN positive) into three sublayers. The SGZ was defined as the 1-2 cell layer between the hilus and the granular layer that was NeuN negative. Thirty to $150 \beta$-Gal and NeuN double-positive cells were examined in each mouse ( $n=6$ for each). The number of phospho-ERK-positive cells was measured on sections through the hippocampus ( 6 sections per mouse, $n=5-6$ for each) and presented as the average number in the SGZ region on a $5-\mu \mathrm{m}$-thick section. For the analysis of dendritic morphology, Dcx-positive cells with at least tertiary and mostly intact dendritic branches were selected, and 30 - $\mu$ m-thick $z$-series of confocal images of each cell were collected. Dendritic processes were traced and quantified (Sholl analysis) using Adobe and MetaMorph software on a minimum of 10 cells per mouse and 9-10 mice for each genotype and treatment. Fluorescent images of immunocytochemistry for BrdU and Ki67 were captured and analyzed using the MetaMorph software, with all cells costained with DAPI to denote the location of nuclei. Eight subfields were selected at random for each genotype and staining, and 90-170 cells in each subfield were analyzed. Fluorescent images of Dcx and phospho-ERK coimmunostaining were captured, and 20 Dcx-positive cells in each mouse $(n=3$ mice for each genotype) were analyzed for the expression of phospho-ERK, from which the percentage was calculated. Student's $t$ test was used to determine statistical differences between two groups of samples, while ANOVA was used for the comparisons of more than two groups, followed by Bonferroni post hoc analyses. A value of $p<0.05$ was deemed statistically significant.

Antidepressant treatments and behavioral analyses. Adult littermate mice were used for antidepressant treatments and the examination of depression- and anxiety-like behaviors. For X-Gal analysis, R26 ${ }^{\text {Nestin }}$ mice treated with saline/imipramine for $21 \mathrm{~d}$, or saline/fluoxetine for $28 \mathrm{~d}$, were collected within $24 \mathrm{~h}$ of the last injection ( $n=3$ for each). Cohorts of male control and DTA ${ }^{\text {Nestin }}$ mice were injected with saline, fluoxetine $(18 \mu \mathrm{g} / \mathrm{g})$ or imipramine $(20 \mu \mathrm{g} / \mathrm{g})$ for $21 \mathrm{~d}(n=9-10$ for each genotype and treatment). Subchronic antidepressant treatment was performed by injecting separate groups of male control and NF1 ${ }^{\text {Nestin }}$ mice with saline, fluoxetine, or imipramine daily for $7 \mathrm{~d}(n=9-10$ for each). These two sets of animals were tested in the novelty-suppressed feeding test (NSFT) and tail-suspension test (TST) paradigms following protocols described previously (Santarelli et al., 2003; Li et al., 2008). Briefly, immediately after the last dose of antidepressant or saline, mice were deprived of food for $24 \mathrm{~h}$ and then subjected to NSFT. Individual mice were placed in a well lit box $(23 \times 23 \times 10 \mathrm{inch})$ for up to $10 \mathrm{~min}$ where a food pellet was presented in the center. The latency to feed was rated by investigators blind to genotypes, and "feeding" was scored when the mouse sat on its haunches and ate using forepaws. Mice were then returned to their home cage, where food consumption in the next $5 \mathrm{~min}$ was monitored. Twenty-four hours afterward, the same groups of mice were subjected to the TST, where individual mice were suspended from a horizontal bar with adhesive tape. Activity within a 6 min session was video-recorded, and the length of immobility was measured. To assess the basal depression- and anxiety-like behaviors of 8-and 11-month-old mice, male control and NF1 ${ }^{\text {Nestin }}$ mice were tested in the NSFT, TST, and forced-swim test (FST; $n=10-13$ for each genotype and age), in the order listed and with at least a $24 \mathrm{~h}$ interval between tests. FST was conducted as previously described (Krishnan et al., 2007). Individual mice were placed in a $4 \mathrm{~L}$ beaker $(16.5 \mathrm{~cm}$ diameter $)$ of water $\left(21-25^{\circ} \mathrm{C}\right)$ to a depth of $17.8 \mathrm{~cm}$. Mice remained in the water for $6 \mathrm{~min}$ and were then removed and allowed to dry in a clean cage before returning to their home cage. Water was changed between each subject. The mice were video-recorded from the side, and an investigator blind to the genotypes scored immobility, defined as no volitional body or limb movement in the last 4 min. Separate cohorts of 8-month-old control and NF1 Nestin mice ( $n=6-7$ for each genotype, housing condition, and antidepressant treatment) were subjected to chronic mild stress (CMS) for 5 weeks, using a regimen of unpredictable mild stressors that included $45^{\circ}$ cage tilting, placement in the cage of a different male, inversion of dark/light cycle, lights on during dark cycle, short-term confinement, and soiled or no bedding. Stressors were presented at varying time points during the day. Saline or antidepressant treatments were given during the last 3 
A

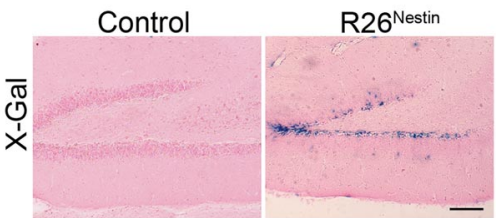

B
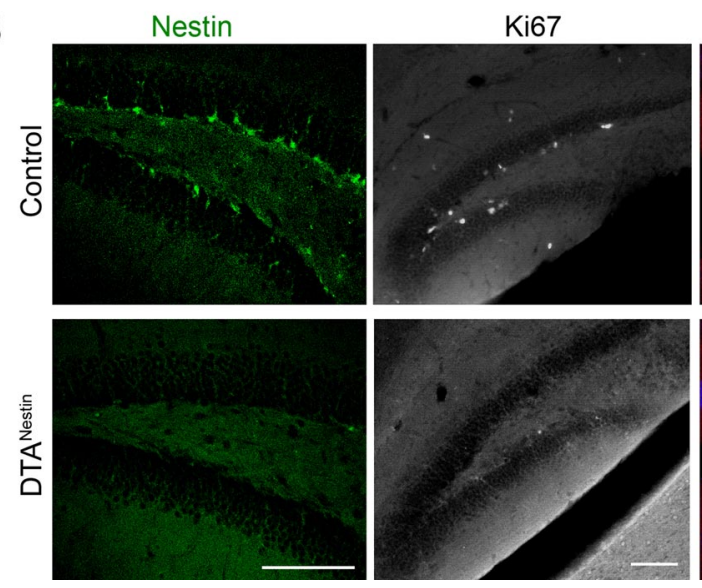

Dcx NeuN
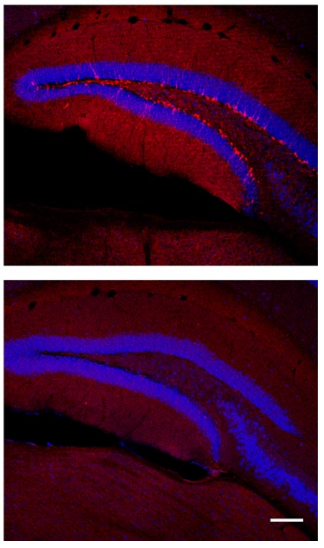

Figure 1. Nestin-CreER ${ }^{T 2}$ labels adult hippocampal NPCS. A, X-Gal staining on DG sections of control and R26 ${ }^{\text {Nestin }}$ mice at 2.5 months. Vehicle or tamoxifen was given at 2 months. Scale bar, $100 \mu \mathrm{m}$. $\boldsymbol{B}$, Representative confocal images of the DG immunostained for Nestin (green), Ki67 (white), Dcx (red), and NeuN (blue) at 3.5 months of age. Note the loss of Nestin-, Ki67-, and Dcx-immunopositive cells in the DTA ${ }^{\text {Nestin }}$ mice. Scale bar, $100 \mu \mathrm{m}$.

weeks. An observer blind to genotype and treatment assessed coat condition by scoring each of 8 areas: head, neck, dorsal coat, ventral coat, genital area, tail, forepaws, and hindpaws. A score of 0 was given for a well groomed state, and 1 for a poorly kept area. The sums of scores in all areas were used for quantitative comparison. To measure self-grooming, animals were splashed with a moderate amount of $10 \%$ sucrose solution on the coat, and the frequency of self-grooming in home cages was recorded during a $5 \mathrm{~min}$ period. TST was performed $72 \mathrm{~h}$ after the last dosage of saline/antidepressant. Mice were killed $24 \mathrm{~h}$ after the last behavioral test for tissue collection.

\section{Results}

We previously demonstrated that the tamoxifen-inducible form of Cre recombinase, CreER ${ }^{\mathrm{T} 2}$, when expressed under neuralspecific regulatory elements of the Nestin gene, enables temporal control of recombination specifically in adult NPCs (Chen et al., 2009). By crossing the Nestin-CreER ${ }^{T 2}$ mice to the R26 reporter mice (Soriano, 1999), and inducing Cre-mediated recombination with tamoxifen, hippocampal NPCs and their progeny could be labeled and lineage traced (Fig. $1 A ;$ R $26^{\text {Nestin }}$ mice, tamoxifen induction at 2 months of age). It is well documented that chronic antidepressants increase hippocampal proliferation, differentiation and maturation of newly born neurons (Li et al., 2008; Wang et al., 2008). We confirmed that chronic treatment of imipramine $(20 \mu \mathrm{g} / \mathrm{g})$, or fluoxetine $(18 \mu \mathrm{g} / \mathrm{g})$ significantly increased the number of X-Gal-positive cells in the dentate gyrus of R26 ${ }^{\text {Nestin }}$ mice, by $54.8 \%$ and $63.0 \%$, respectively. These findings were consistent with prior observations (Encinas et al., 2006), and demonstrate that the Nestin-CreER ${ }^{T 2}$ transgene can facilitate the monitoring of this population of NPCs.

To effectively study neurogenesis after $N f 1$ deletion in SGZ progenitors, high-efficiency Cre-mediated recombination must be achieved. Therefore, to determine the efficiency of the Nestin$\mathrm{CreER}^{T 2}$ transgene in mediating recombination, we used a Cre-dependent toxin-based cell-ablation approach, that allows identification of any NPCs in the SGZ that evade recombination because they would survive. A mouse line harboring a silent allele of the diphtheria toxin subunit A (DTA) gene (Brockschnieder et al., 2006), that becomes active upon Cre-mediated recombination, was crossed with NestinCreER ${ }^{T 2}$ mice. Without tamoxifen, the $D T A^{\text {flox }}$;Nestin-CreER $R^{T 2}$ mice were indistinguishable from their littermate controls in brain weight and hippocampal structural morphology (data not shown). When treated with vehicle (control group) or tamoxifen (DTA ${ }^{\text {Nestin }}$ group) at the age of 2 months and analyzed 2 weeks later, the DTA ${ }^{\text {Nestin }}$ mice had almost no detectable Nestin-expressing cells in the SGZ ( $<5 \%$ compared with controls, Fig. $1 B$ ) or SVZ (data not shown). This was echoed by near complete loss of proliferating cells (Ki67-positive), and immature neurons (Dcx-positive) at 3.5 months of age (Fig. $1 B$ ); however, existing neurons and glia appeared unaffected by tamoxifen induction (data not shown). These results are consistent with a previous report demonstrating efficient ablation of Dcx-positive cells in the adult dentate gyrus upon tamoxifen induction in mice carrying the Nestin-CreER ${ }^{T 2}$ and NSEDTA transgenes (Imayoshi et al., 2008). Our results confirm that the Nestin-CreER ${ }^{T 2}$ line used in the present study is highly efficient in targeting the vast majority of NPCs in the SGZ.

\section{Nf1 deletion increases adult hippocampal neurogenesis}

We next targeted Nf1 in adult NPCs using mice harboring two conditional (flox) alleles of $N f 1$ and the Nestin-CreER ${ }^{T 2}$ transgene, treated with tamoxifen at 2 months of age ( $N F 1^{\text {Nestin }}$ mice). The NF1 ${ }^{\text {Nestin }}$ mice appeared healthy and were grossly indistinguishable from control mice (data not shown). Recombination of the flox alleles in NF1 $1^{\text {Nestin }}$ mice was confirmed in DG-derived NPCs by PCR (Fig. 2A). To visualize the extent of Cre-mediated recombination, we incorporated the $R 26$ reporter allele into the $\mathrm{NF} 1^{\text {Nestin }}$ mice and examined X-Gal-positive NPCs and their progeny (R26;NF1 ${ }^{\text {Nestin }}$ mice; Fig. $2 B$ ). Compared with agematched R26 ${ }^{\text {Nestin }}$ mice, R26;NF1 ${ }^{\text {Nestin }}$ mice displayed similar numbers and distribution of X-Gal-positive cells at 2.5 and 3 months (Fig. 2C; data not shown). Additional analysis, including immunostaining for Ki67, Dcx, BrdU, and NeuroD demonstrated a similar number of proliferating cells and newly born neurons in the SGZ (Saline groups; see Fig. $4 F-I$; data not shown). Thus, 1 month after ablation of Nf1 in adult NPCs, basal hippocampal neurogenesis was not significantly affected.

At 1 month after tamoxifen induction (3 months of age), few $\beta$-Gal-positive cells expressed a mature neuronal marker $(\mathrm{NeuN})$, but rather expressed markers of undifferentiated NPCs and immature neurons (Fig. 2D). Six months post-tamoxifen induction ( 8 months of age), the X-Gal-positive cell population expanded from the SGZ into the inner granular layer, indicative of progressive neuronal differentiation (Fig. $2 E$; see Fig. $2 G$ for diagram). By comparison, the R26;NF1 ${ }^{\text {Nestin }}$ mice had a higher number of X-Gal-positive cells, with more robust migration into the inner and outer portions of the granular layer (Fig. 2E). Consistent with the notion that newly generated cells in the adult DG preferentially assume neuronal fate, we found a majority of 
B

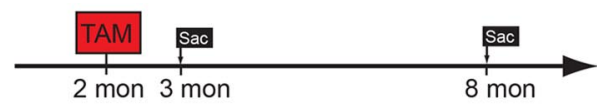

A

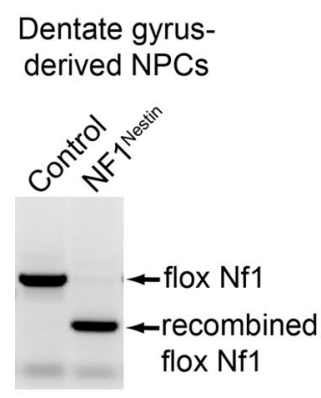

$\mathbf{F}$

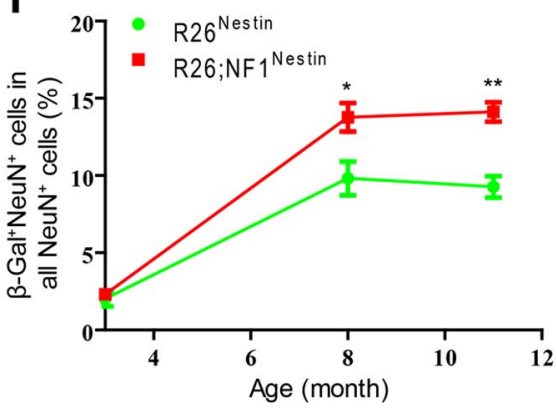

D

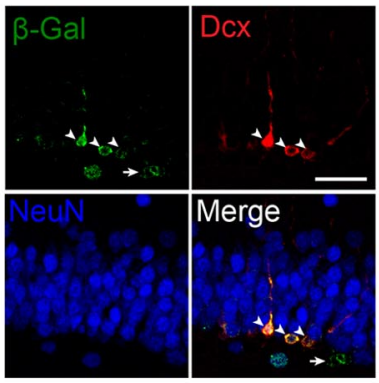

E

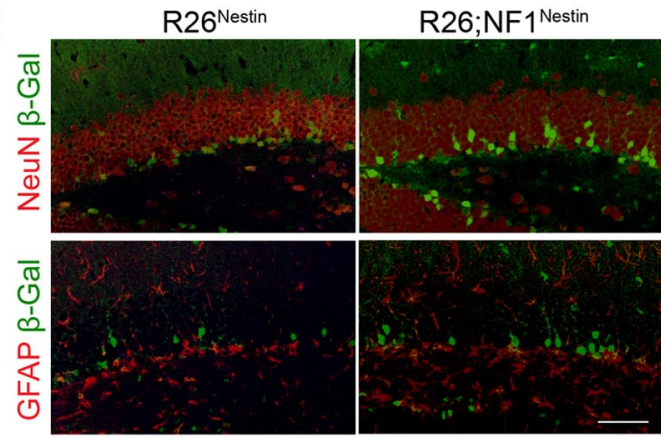

Outer GL

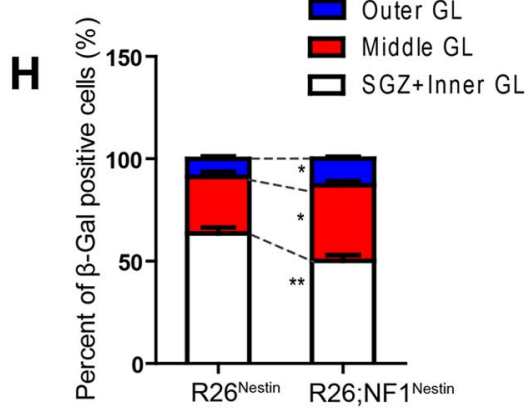

Figure 2. Ablation of Nf1 in adult NPCs in vivo.A, PCR demonstrating Nestin-CreER ${ }^{T 2}$-mediated recombination of the flox Nf1 alleles in DG-derived adult NPCs. Mice were given tamoxifen at 2 months of age. NPCs were derived from DG at 3 months. $B$, Diagram of tamoxifen induction regimen. Mice were induced with tamoxifen at 2 months of age and killed at 3 months or 8 months of age. $C, R 26$ reporter revealed enhanced long-term neurogenesis in the DG of NF1 ${ }^{\text {Nestin }}$ mice. Mice were given tamoxifen at 2 months and examined at 3 or 8 months of age. Images show representative X-Gal staining. Bottom show higher-magnification view of the boxed areas. TAM, tamoxifen. Scale bar, $100 \mu \mathrm{m}$. D, Coimmunostaining for $\beta$-Gal (green), Dcx (red), and NeuN (blue) at 3 months ( 1 month post-tamoxifen). Note that most recombined cells $\left(\beta\right.$-Gal $\left.{ }^{+}\right)$did not express NeuN, but colocalized with the immature neuronal marker (Dcx). Scale bar, $50 \mu \mathrm{m}$. $\boldsymbol{E}$, In the DG of 8-month-old mice, adult-generated cells $\left(\beta\right.$-Gal $\left.{ }^{+}\right)$predominantly assumed neuronal fate $\left(\mathrm{NeuN}^{+}\right.$). Images show representative double immunostaining for $\beta$-Gal (green) and NeuN (red, top) or GFAP (red, bottom). Scale bars, $100 \mu \mathrm{m}$. $F$, Quantification of $\beta$-Gal and NeuN double immunostaining revealed significant increase in the proportion of new-born neurons $\left(\beta-G a l{ }^{+} \mathrm{NeuN}^{+}\right)$in all NeuN ${ }^{+}$granule neurons in NF1 ${ }^{\text {Nestin }}$ mice. ANOVA (GLM) revealed significant effects of time $\left(F_{(2,25)}=101.6, p<0.0001\right)$, genotype $\left(F_{(1,25)}=21.49, p<0.0001\right)$, and the interaction of the two $\left(F_{(1,25)}=4.621, p<0.0196\right) . N=4-6$ for each genotype and age. $\boldsymbol{G}, \boldsymbol{H}$, Adult-born neurons $\left(\beta\right.$-Gal $\left.{ }^{+}\right)$ in the DG of NF1 ${ }^{\text {Nestin }}$ mice exhibited increased migration into the middle and outer portions of the granular layers. GL, granular layer. $N=6$ for each. Results are mean $+\mathrm{SEM}$. ${ }^{*} p<0.05$, ${ }^{* *} p<0.01$.

$\beta$-Gal-positive cells coexpressing NeuN but not GFAP (Fig. 2 E). In concert with the $\mathrm{X}$-Gal staining (Fig. $2 C$ ), we found more $\beta$-Gal-positive neurons in $\mathrm{R} 26 ; \mathrm{NF} 1^{\text {Nestin }}$ mice at 8 and 11 months of age (Fig. 2E, F; data not shown). Quantitative analysis revealed that a higher percentage of $\beta$-Gal-positive neurons was found in the middle and outer granular layers in the 8-month-old R26;NF1 ${ }^{\text {Nestin }}$ mice (Fig. 2G,H). Further analysis of $\beta$-Gal costaining revealed that the proportion of cells expressing $\mathrm{NeuN}$ or GFAP among all $\beta$-Gal-positive cells was unaffected by genotype (data not shown), suggesting relatively normal lineage commitment of newborn cells from adult NPCs in the absence of Nf1. These results demonstrate that ablation of Nf1 in adult NPCs increases neurogenesis in the DG.

\section{Activation of ERK signaling in $\mathrm{Nf1}^{-/-} \mathrm{NPCs}$ and immature neurons}

As described above, Nf1 loss in adult hippocampal NPCs beginning at 2 months of age resulted in an obvious increase in neuro- genesis by 8 months of age (Fig. 2C,E). It is known that the ERK and PI3K signaling cascades can be genetically activated by loss of the Nf1 gene (Klesse and Parada, 1998). We therefore examined the levels of phosphorylated ERK and AKT in the hippocampus. At 3 months of age, control and $N F 1^{\text {Nestin }}$ mice exhibited phospho-ERK immunostaining in the axons of dentate granule neurons along the mossy fiber pathway (Fig. $3 A$, insets in top panels), and occasionally in pyramidal neurons of the CA1 regions (data not shown). In the SGZ, however, we observed phospho-ERK-positive cell bodies in NF1 ${ }^{\text {Nestin }}$ mice but not in littermate controls (Fig. $3 A$; number of positive cells per section: $0.33 \pm 0.16$ in control mice; $3.44 \pm 1.00$ in NF1 ${ }^{\text {Nestin }}$ mice). Many of the phospho-ERK-positive SGZ cells colocalized with the immature neuronal marker Dcx (Fig. 3B), but not mature neuronal marker NeuN (Fig. 3C). In addition, some phospho-ERKpositive cells colabeled with Nestin (Fig. 3D) or Sox2, markers for adult NPCs (Fig. 3E). We note that not all NPCs or immature neurons identified with the cell type-specific markers displayed ele- 
A
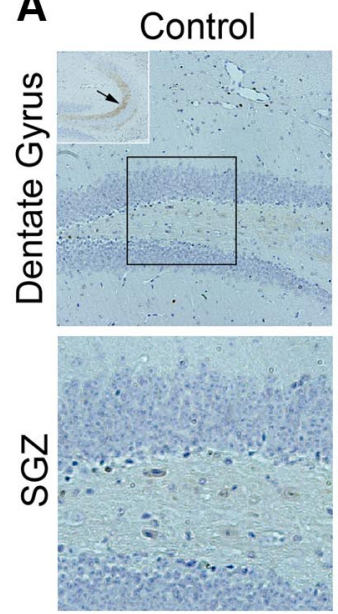

D

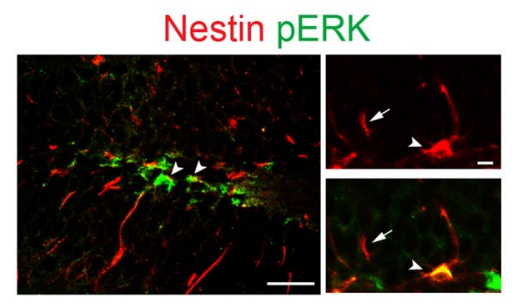

G

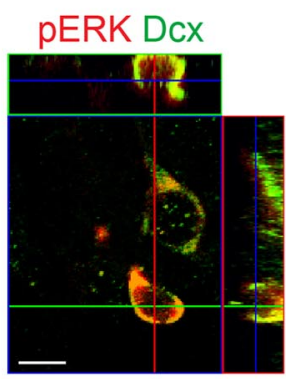

I

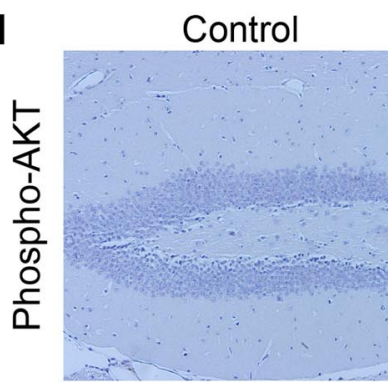

NF1 ${ }^{\text {Nestin }}$
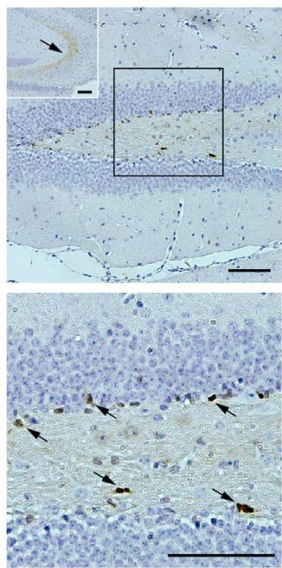

E
B

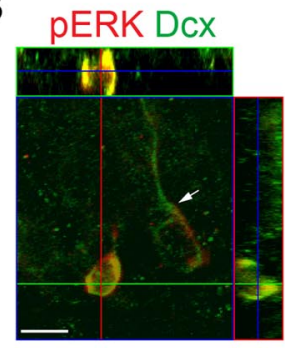

F
C

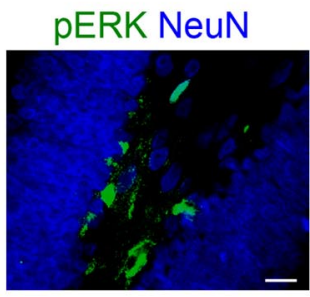

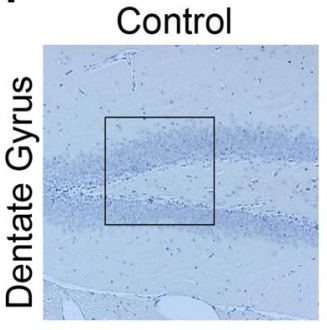

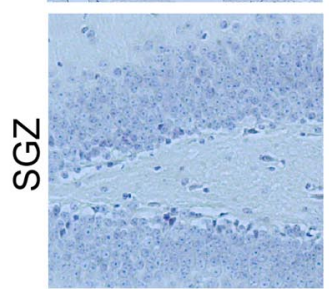

NF1 Nestin
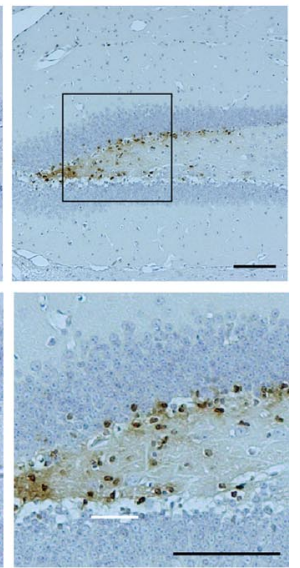

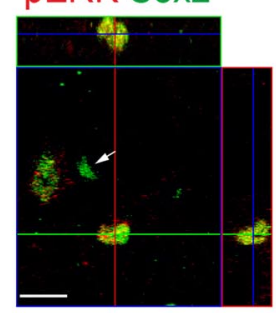

H
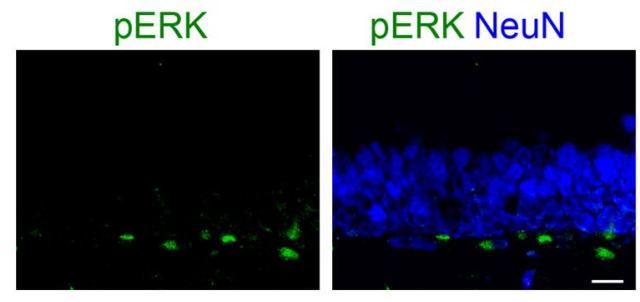

\section{NF $1^{\text {Nestin }}$}
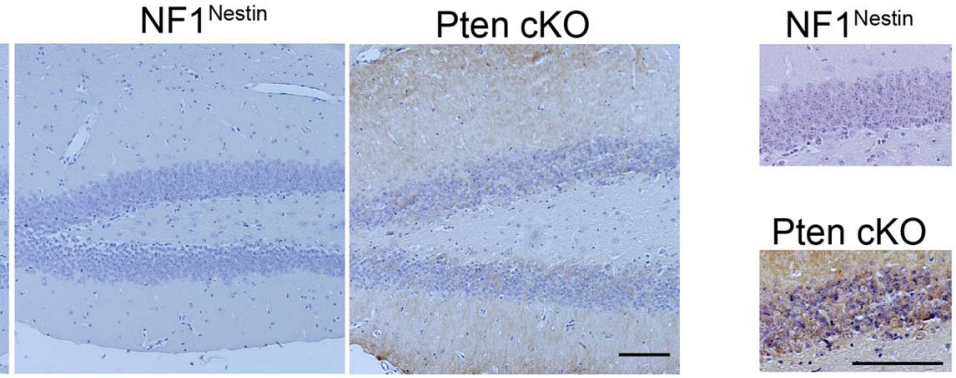

Figure 3. Nf1 ablation leads to ERK activation in NPCs and immature neurons. A, At 3 months of age, Nf1 ablation increased the number of phospho-ERK-immunopositive cell bodies in the SGZ. Bottom shows higher-magnification view of the boxed areas. Insets in the top show phospho-ERK-immunopositive mossy fiber pathway. Arrows indicate immunoreactivity. Scale bars, $100 \mu \mathrm{m}$. $\boldsymbol{B}-\boldsymbol{E}$, Coimmunostaining demonstrated that phospho-ERK-positive cells colocalized with $\operatorname{Dcx}(\boldsymbol{B})$, Nestin (D), and Sox2 (E), but not NeuN (C). P, Phosphorylated. Arrows indicate cells with lack of colocalization. Arrowheads indicate colocalization. Scale bars, $30 \mu \mathrm{m}$ (left) and $5 \mu \mathrm{m}$ (right) for Nestin (D), $20 \mu \mathrm{m}$ for all else. $\boldsymbol{F}$, At 8 months of age, NF ${ }^{\text {Nestin }}$ mice had dramatically more phospho-ERK-positive cell bodies in the SGZ. Scale bars, $100 \mu \mathrm{m} . \mathbf{G}, \boldsymbol{H}$, Long-term ablation of $N f 1$ in adult NPCs led to ERK activation in Dcx ${ }^{+}$new neurons $(\boldsymbol{G})$, but not NeuN ${ }^{+}$mature neurons $(\boldsymbol{H})$. $\boldsymbol{P}$, Phosphorylated. Scale bars: $\mathbf{G}, 15 \mu \mathrm{m} ; \boldsymbol{H}, 20 \mu \mathrm{m}$. I, Nf1 ablation in adult NPCs did not lead to activation of AKT in vivo. Enhanced phospho-AKT immunoreactivity was observed in the DG granular and molecular layers of Pten conditional knock-out (cKO) mice, but not in control or NF1 ${ }^{\text {Nestin }}$ mice. Scale bar, $100 \mu \mathrm{m}$.

vated phospho-ERK. Quantitative analyses revealed that $36.67 \pm$ $4.41 \%$ of Dcx-positive cells expressed phospho-ERK, suggesting that ablation of $N f 1$ led to partial activation of ERK signaling in NF1 ${ }^{\text {Nestin }}$ mice at this relatively early stage (1 month post-tamoxifen).

We next examined the status of ERK signaling in 8-month-old $N F 1^{\text {Nestin }}$ mice. In the SGZ, we detected a significant increase in the number of phospho-ERK-positive cells compared with controls and younger NF1 $1^{\text {Nestin }}$ counterparts (Fig. $3 F$; number of positive cells per section: $0.26 \pm 0.16$ in control mice; $30.86 \pm$ 9.82 in NF1 ${ }^{\text {Nestin }}$ mice; $n=6$ for each; $\left.p<0.05\right)$. Similar to 3 -month-old NF1 ${ }^{\text {Nestin }}$ mice, coimmunostaining revealed that the phospho-ERK-positive cells expressed markers of immature 
neurons such as doublecortin (Fig. 3G), but not markers of mature neurons, such as NeuN (Fig. $3 H$ ). In addition, a high level of ERK activity was seen in almost all Dcx-positive cells (98.33 $\pm 1.67 \%)$, indicating increased penetrance of ERK activation in 8 -month-old NF1 ${ }^{\text {Nestin }}$ mice compared with their 3-month-old counterparts. Together, these findings demonstrate that ablation of Nf1 in adult NPCs causes progressive activation of the ERK pathway.

We also examined phospho-AKT but observed no evidence of activity in mice of either genotype or age, although intense staining was seen within the SGZ, granular layer and molecular layer in brain tissues from Pten conditional knock-out mice, in which activation of the AKT pathway is expected in Pten $^{-1-}$ cells (Zhou et al., 2009) (Fig. 3I). Thus, Nf1 ablation in adult NPCs leads to cellautonomous activation of ERK but not AKT.

Loss of $N f 1$ facilitates behavioral and neurogenic response to antidepressants Hippocampal neurogenesis has been implicated in the behavioral effects of chronic antidepressants (Santarelli et al., 2003; Airan et al., 2007; Li et al., 2008; Wang et al., 2008; David et al., 2009). Consistent with this, the DTA ${ }^{\text {Nestin }}$ mice, which are incapable of undergoing neurogenesis (Fig. 1B), showed muted behavioral response to chronic fluoxetine (18 $\mu \mathrm{g} / \mathrm{g})$ or imipramine $(20 \mu \mathrm{g} / \mathrm{g})$ in the NSFT and the Tail-Suspension Test (Fig. $4 A, B)$, thus reflecting a lack of change in anxiety- and depression-like behaviors. These data provided genetic confirmation that acute depletion of adult NPCs in mice abrogates behavioral response to chronic antidepressants in the NSFT and TST.

We next tested whether acute ablation of Nf1 in adult NPCs would have opposing effects on behavioral response to antidepressant. At 3 months of age, basal level anxiety- and depression-like behaviors as measured by NSFT, TST, and FST were indistinguishable in control and NF1 ${ }^{\text {Nestin }}$ mice (Saline groups in Fig. 4D,E; data not shown). Furthermore, both groups showed significant behavioral improvements in these behavioral tests after chronic fluoxetine or imipramine treatment, compared with saline-treated mice

(21 d regimen, data not shown). We next subjected control and $\mathrm{NF} 1^{\text {Nestin }}$ mice to a shortened antidepressant treatment paradigm, in which animals were treated with saline, fluoxetine (18 $\mu \mathrm{g} / \mathrm{g})$ or imipramine $(20 \mu \mathrm{g} / \mathrm{g})$ for $7 \mathrm{~d}$, and tested in the NSFT and TST paradigms on day 8 and 9 , respectively (Fig. $4 C$ ). The $\mathrm{NF} 1^{\text {Nestin }}$ mice receiving subchronic fluoxetine or imipramine

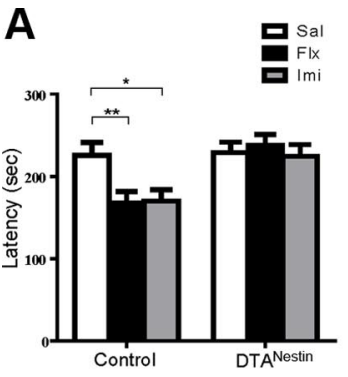

B

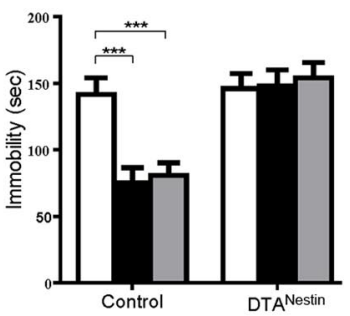

E
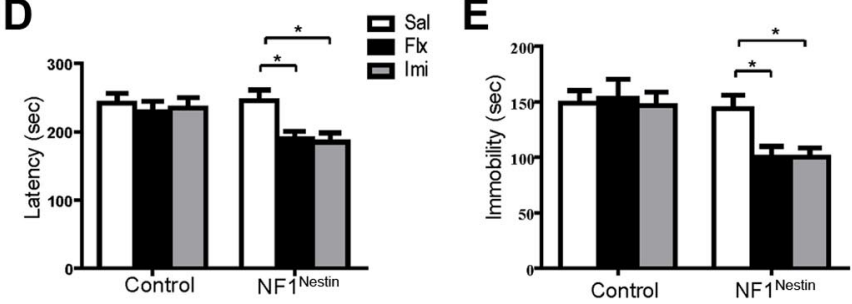

F

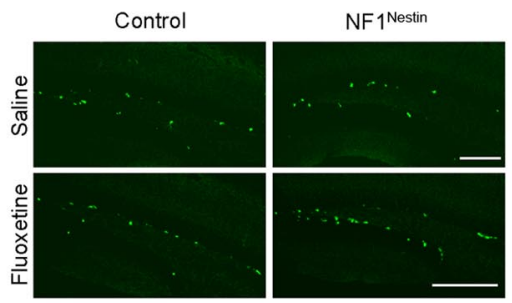

G

H

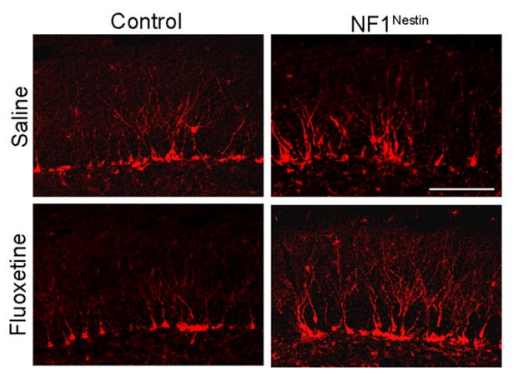

C

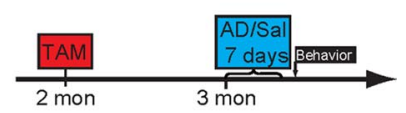

Figure 4. $\quad N f 1$ ablation in adult NPCs enables rapid behavioral and neurogenic response to subchronic antidepressants. $\boldsymbol{A}$, In the NSFT, chronic fluoxetine or imipramine shortened the latency to feed in control mice, indicating lowered anxiety. DTA ${ }^{\text {Nestin }}$ mice showed no behavioral changes after treatments. $N=9-10$ for each. ANOVA (GLM) found significant effects of genotype $\left(F_{(1,52)}=\right.$ $14.07, p=0.0004)$, and the interaction of genotype and treatment $\left(F_{(2,52)}=3.214, p=0.0483\right)$. Sal, Saline; Flx, fluoxetine; Imi, imipramine. $\boldsymbol{B}$, The total length of immobility in the TST reflects the level of depression-like behavior and could be reduced by chronic fluoxetine or imipramine in control mice, but not in DTA ${ }^{\text {Nestin }}$ mice. $N=9-10$ for each. ANOVA (GLM) found significant effects of antidepressant treatment $\left(F_{(2,52)}=4.603, p=0.0144\right)$, genotype $\left(F_{(1,52)}=28.81, p<0.0001\right)$, and the interaction of the two $\left(F_{(2,52)}=6.103, p=0.0042\right)$.C, Diagram of subchronic antidepressant treatment regimen. Mice were treated with vehicle or tamoxifen at 2 months of age and exposed to saline or antidepressants at 3 months of age for $7 \mathrm{~d}$. TAM, Tamoxifen; Sal, saline; $A D$, antidepressant. $D, E$, Subchronic antidepressants reduced the latency to feed in the NSFT $(\boldsymbol{D})$ and the length of immobility in the TST $(\boldsymbol{E})$ in the NF1 ${ }^{\mathrm{Nestin}}$ mice, while control mice did not display significant behavioral responses. NSFT: $F_{(2,51)}=3.715, p=0.0312$ for treatment; $F_{(1,51)}=5.896, p=0.0187$ for genotype. IST: $F_{(1,51)}=12.76, p=0.0008$ for genotype. $\boldsymbol{F}, \mathbf{G}$, Subchronic fluoxetine or imipramine increased the number of Ki67-positive (green) proliferating cells in the DG of NF1 ${ }^{\text {Nestin }}$ but not control mice. ANOVA (GLM) revealed significant effects of treatment $\left(F_{(2,52)}=6.279, p=0.0036\right)$, genotype $\left(F_{(1,52)}=29.74, p<\right.$ $0.0001)$, and the interaction of the two $\left(F_{(2,52)}=4.730, p=0.0130\right)$. Scale bar, $100 \mu \mathrm{m}$. $\boldsymbol{H}, \boldsymbol{I}$, The numbers of Dcx-positive (red) newborn neurons in the DG of NF1 Nestin but not control mice increased after subchronic fluoxetine or imipramine treatment. Significant effect of genotype $\left(F_{(1,52)}=22.69, p<0.0001\right)$ was found. Scale bar, $100 \mu \mathrm{m}$. Results are mean + SEM. ${ }^{*} p<0.05,{ }^{* *} p<0.01,{ }^{* * *} p<0.001$.

displayed significantly decreased latency to feed in the NSFT compared with those receiving saline (Fig. 4D). We found that control mice of all treatment groups performed similarly, confirming previous reports that this duration of antidepressant exposure was not sufficient to produce behavioral change in the NSFT paradigm (Santarelli et al., 2003; Wang et al., 2008). 
A
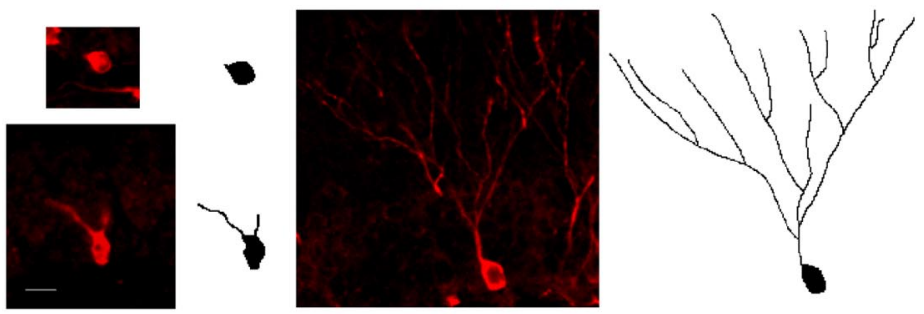

C

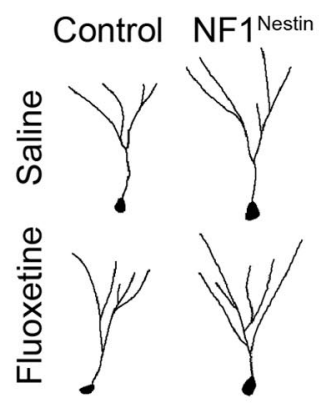

D

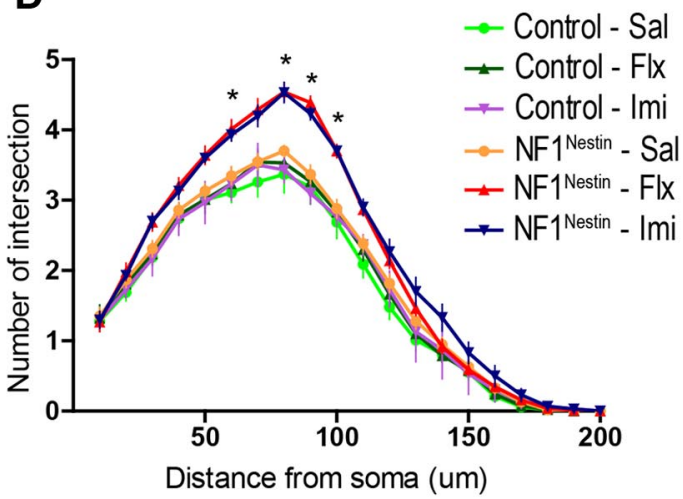

G

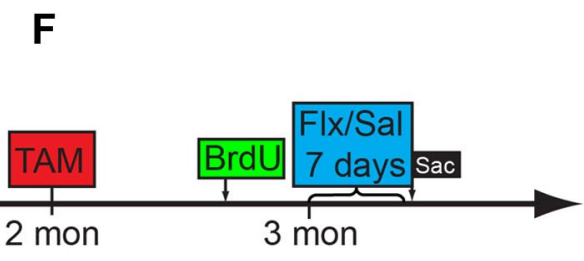

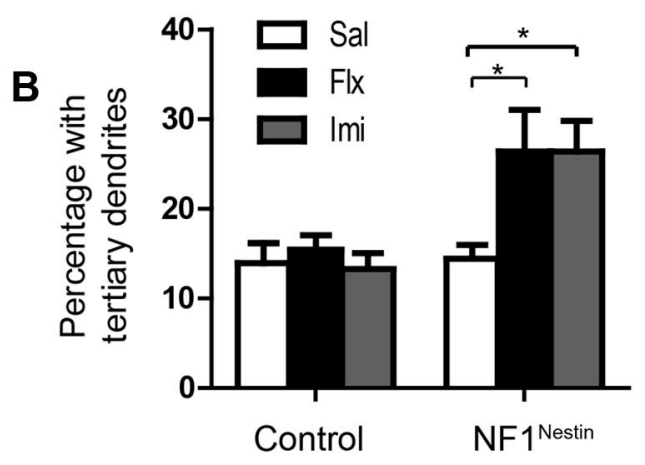

E
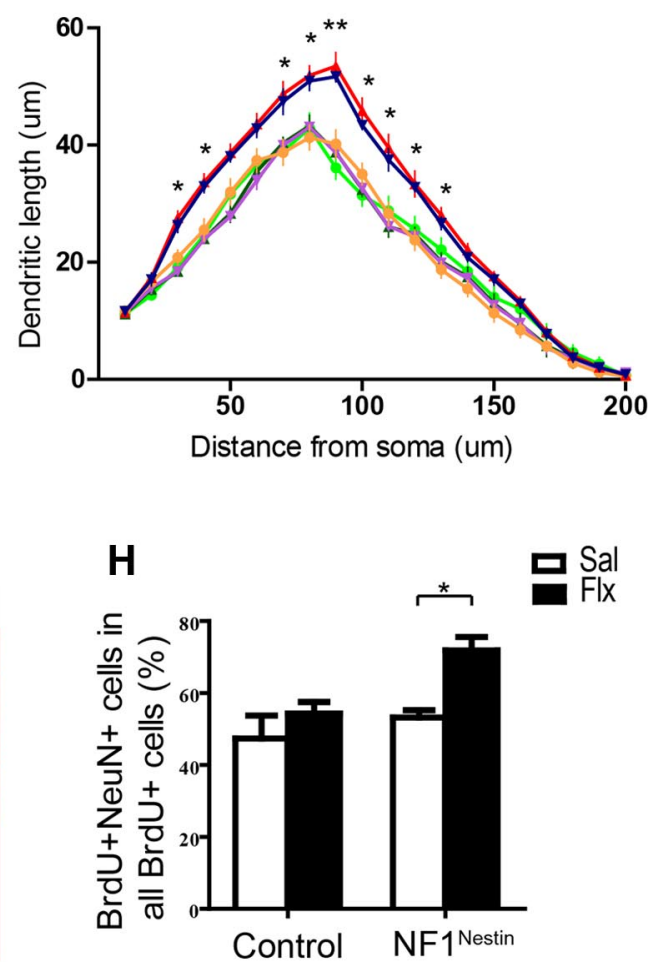

Figure 5. Subchronic fluoxetine accelerates neuronal maturation in NF1 ${ }^{\text {Nestin }}$ mice. $A$, Immunostaining for $D c x$ (red) revealed the dendritic morphology of immature neurons. $B$, Subchronic fluoxetine or imipramine increased the percentage of Dcx-positive neurons that harbored tertiary dendrites. ANOVA revealed significant effect of treatment $\left(F_{(1,16)}=5.693, p=0.0297\right)$. Sal, Saline; Flx, fluoxetine; Imi, imipramine. C, Tracing of representative Dcx-positive cells in the DG of saline- or fluoxetine-treated control and NF ${ }^{\text {Nestin }}$ mice. $\boldsymbol{D}, \boldsymbol{E}$, Subchronic fluoxetine or imipramine increased the number of dendritic intersections $(\boldsymbol{D})$ and dendritic length $(\boldsymbol{E})$ of DCx-positive cells in NF1 ${ }^{\text {Nestin }}$ but not control mice. ANOVA post hoc test of antidepressant-to-saline comparisons found significant difference in NF1 ${ }^{\text {Nestin }}$ mice. $\boldsymbol{F}$ - $\boldsymbol{H}$, BrdU pulse-chase was used to label cells born $7 \mathrm{~d}$ before saline or fluoxetine treatment $(\boldsymbol{F})$. Coimmunostaining for NeuN (red) and BrdU (green) was used to identify $14-\mathrm{d}$-old mature neurons $(\boldsymbol{G})$ born $7 \mathrm{~d}$ before the onset of fluoxetine or saline treatment. Subchronic fluoxetine increased the percentage of all BrdU ${ }^{+}$cells that expressed NeuN in NF1 ${ }^{\text {Nestin }}$ but not control mice $(\boldsymbol{H})$. ANOVA revealed significant effect of treatment $\left(F_{(1,16)}=9.394, p=0.0074\right)$, and genotype $\left(F_{(1,16)}=7.821, p=0.0129\right)$. Results are mean + SEM. ${ }^{*} p<0.05,{ }^{* *} p<0.01$.

Similar findings were obtained with the TST analysis, where $\mathrm{NF} 1^{\text {Nestin }}$ mice receiving antidepressant for $7 \mathrm{~d}$ displayed significantly shorter length of immobility, while the control mice did not respond (Fig. $4 E$ ). We note that the TST was performed $48 \mathrm{~h}$ after the last dose of antidepressant to assess chronic (neurogenesis-dependent) rather than acute (neurogenesisindependent) response.

To examine whether the enhanced behavioral response to antidepressants was coupled with changes in the activity of the DG neurogenic niche, we examined proliferation and new neuron generation. Consistent with previous reports (Malberg et al., 2000), this subchronic fluoxetine or imipramine treatment did not significantly increase proliferation in control mice (Fig. $4 F, G$ ). The NF1 ${ }^{\text {Nestin }}$ mice, however, displayed a significant increase in the number of Ki67-positive cells after subchronic antidepressant treatment (Fig. 4F, G). Quantification of phospho-histone H3-positive cells further confirmed this increase in proliferation (data not shown). Furthermore, the $\mathrm{NF} 1^{\text {Nestin }}$ mice displayed an increased number of Dcxpositive cells, indicating enhanced production of new neurons (Fig. $4 H, I$ ).

Complex dendritic morphology in Dcx-positive cells represents greater cellular maturation (Plümpe et al., 2006; Sahay et al., 2011), and it has been shown that chronic antidepressants can enhance neurogenesis by stimulating new neuron maturation (Wang et al., 2008; David et al., 2009). We analyzed the dendritic morphology of Dcx-positive neurons, and found that subchronic fluoxetine or imipramine increased the number of Dcx-positive cells bearing tertiary dendrites in NF1 ${ }^{\text {Nestin }}$ but not control mice, indicating enhanced maturation of the new neuron pool in re- 
sponse to subchronic fluoxetine (Fig. $5 A, B)$. We next evaluated the dendritic morphology of individual Dcx-positive cells with tertiary dendrites, and found that subchronic fluoxetine or imipramine enhanced the complexity of dendritic branching in NF1 ${ }^{\text {Nestin }}$ mice (Fig. $5 C, D)$, while control mice showed no significant changes. Furthermore, analysis of the total length of dendritic branches showed a similarly enhanced response in $\mathrm{NF} 1{ }^{\text {Nestin }}$ mice (Fig. $5 E$ ).

We next specifically evaluated the effect of subchronic antidepressant on the maturation of already-existing young neurons, by birth-dating cells born $7 \mathrm{~d}$ before the onset of saline or fluoxetine treatment with BrdU, and analyzing their maturation state after treatment (Fig. 5F). By coimmunostaining for BrdU and NeuN (Fig. 5G), we observed that a substantial number of BrdU-positive cells had assumed a mature neuronal phenotype, and that subchronic fluoxetine treatment increased the percentage of BrdU and NeuN double-positive cells in the DG of $\mathrm{NF} 1^{\text {Nestin }}$ mice (Fig. $5 H, n=5$ for each genotype and treatment), but not their littermate controls. These results are consistent with the model that fluoxetine can enhance neurogenesis in NF1 ${ }^{\text {Nestin }}$ mice by promoting the maturation of already-existing young $\mathrm{Nf1} 1^{-1-}$ neurons. Collectively, these findings demonstrate that ablating $N f 1$ in adult NPCs enhances sensitivity to subchronic antidepressant-induced production and maturation of new neurons.

\section{Sustained adult NPC activation and antidepressive-like behavior in aged NF1 ${ }^{\text {Nestin }}$ mice}

To investigate the long-term effects of $N f 1$ deletion on adult DG NPCs, we examined the level of proliferation, differentiation and neuronal maturation in the SGZ of 8-month-old NF1 ${ }^{\text {Nestin }}$ mice in the absence of antidepressant exposure. Immunostaining for Ki67 revealed significantly more dividing cells in the $\mathrm{NF} 1^{\text {Nestin }}$ mice compared with littermate controls, indicating enhanced basal proliferation (Fig. 6 A; number of positive cells: $1022 \pm 69.9$ in control mice; $1670 \pm 57.6$ in NF1 ${ }^{\text {Nestin }}$ mice; $n=6$ for each; $p<0.001)$. As 3 -month-old NF1 ${ }^{\text {Nestin }}$ mice showed normal basal proliferation (Fig. $2 C$ ), additional cohorts of NF1 ${ }^{\text {Nestin }}$ mice were analyzed at 2.5 and 5 months of age ( 2 weeks and 3 months post-tamoxifen, respectively). We found wild-type levels of proliferation in the former, and increased Ki67-positive cells in the latter (Fig. $6 B ; n=4-5$ for each; $p<0.05$ at 5 months). Coinciding with the increase in proliferation, we observed significantly more Dcx-positive cells in the SGZ of 8-month-old $\mathrm{NF} 1^{\text {Nestin }}$ mice, indicating elevated production of immature neurons (Fig. 6 A; number of positive cells: $3086 \pm 356.4$ in control mice; $5420 \pm 187.5$ in NF1 ${ }^{\text {Nestin }}$ mice; $n=6$ for each; $p<0.001$ ). We next evaluated the dendritic morphology of Dcx-positive immature neurons and found increases in dendritic complexity including a higher percentage of Dcx-positive neurons with tertiary dendrites $(11.70 \pm 1.76 \%$ in control mice; $17.24 \pm 0.60 \%$ in NF1 ${ }^{\text {Nestin }}$ mice; $n=4$ for each; $\left.p<0.05\right)$, an increased number of dendritic intersections (Fig. 6C) and longer length (Fig. 6D) compared with controls. Furthermore, using BrdU pulse-chase,
B

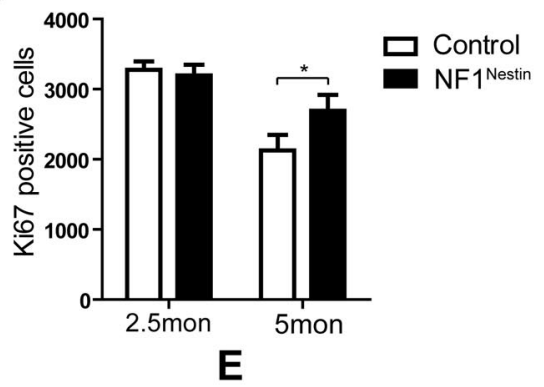

D
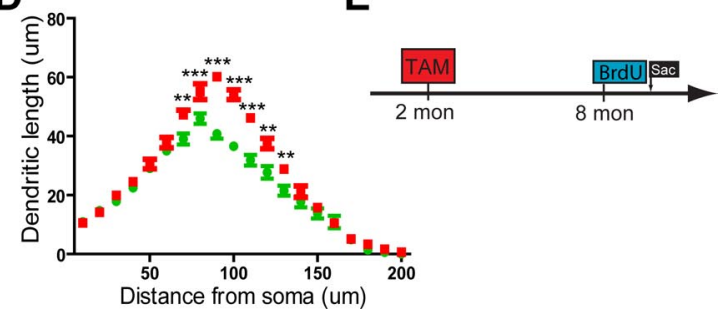

we labeled cells born at 8 months of age (Fig. $6 E$ ), and found that the DG of NF1 ${ }^{\text {Nestin }}$ mice harbored significantly more BrdU and NeuN double-positive neurons after 4 weeks (number of BrdUpositive cells: $324.0 \pm 19.86$ in control mice; $429.6 \pm 28.24$ in NF1 ${ }^{\text {Nestin }}$ mice; $p<0.05$; number of BrdU and NeuN doublepositive cells: $276.0 \pm 17.22$ in control mice; $376.8 \pm 22.96$ in NF1 ${ }^{\text {Nestin }}$ mice; $p<0.01 ; n=5$ for each). Thus, coincident with activation of the ERK signaling pathway, ablation of $N f 1$ in adult NPCs appears to elicit spontaneous activation of NPC proliferation, increased new neuron production, and enhanced maturation. While these data are intriguing, the mechanism by which this increase in proliferation over time occurs is not completely understood and warrants further investigation.

To examine whether genetic activation of adult NPCs produces antidepressive-like behavioral changes, we tested cohorts of 8-month-old mice in the TST paradigm. Compared with littermate control mice, NF1 ${ }^{\text {Nestin }}$ mice displayed significantly shorter length of immobility suggesting decreased depressionlike behavior $(160.58 \pm 9.81 \mathrm{~s}$ for control mice; $128.36 \pm 11.91 \mathrm{~s}$ for NF1 ${ }^{\text {Nestin }}$ mice; $p<0.05 ; n=11-12$ ). This was further confirmed in the FST, in which NF1 ${ }^{\text {Nestin }}$ mice displayed decreased immobility $(106.08 \pm 6.65 \mathrm{~s}$ for control mice; $77.92 \pm 7.96 \mathrm{~s}$ for NF1 ${ }^{\text {Nestin }}$ mice; $\left.p<0.05 ; n=12-13\right)$. We used the NSFT to measure anxiety-like behaviors, and found a downward trend in latency to feed in NF1 ${ }^{\text {Nestin }}$ mice at 8 months of age (data not shown), and significantly lower latency in a separate cohort of 11-month-old NF1 ${ }^{\text {Nestin }}$ mice, suggesting that lack of Nf1 conferred greater resistance to novelty-induced acute anxiety $\left(273.0 \pm 16.40 \mathrm{~s}\right.$ for control mice; $226.0 \pm 12.99 \mathrm{~s}$ for NF1 ${ }^{\text {Nestin }}$ mice; $p<0.05 ; n=10$ for each). We further confirmed that at 11 months NF1 ${ }^{\text {Nestin }}$ mice had higher levels of phospho-ERK expression in the SGZ, and increased NPC proliferation and neurogenesis (data not shown). Together, these findings suggest that enhanced neurogenesis influenced basal anxiety- and depression-like behaviors. 
A

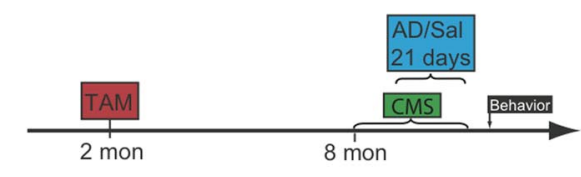

B

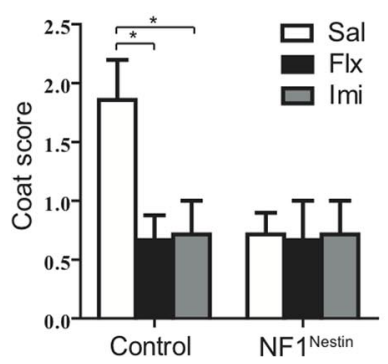

C

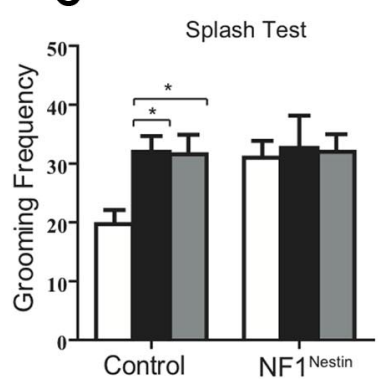

D

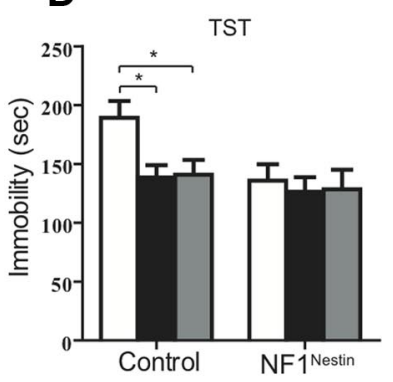

Figure 7. Long-term Nf1 ablation leads to antidepressive-like behaviors. $A$, Diagram of the 5 week CMS paradigm. AD, antidepressant; Sal, saline. $B, C$, In control mice, chronic fluoxetine and imipramine reversed CMS-induced deterioration in coat condition $(\boldsymbol{B})$ and increased grooming frequency in the splash test $(\boldsymbol{C})$. NF1 ${ }^{\text {Nestin }}$ mice were unaffected by CMS or antidepressant treatment ( $\boldsymbol{B}, \boldsymbol{C}$ ). Flx, fluoxetine; Imi, imipramine. D, Chronic fluoxetine and imipramine reduced TST immobility in CMS-control mice, while CMS-NF1 ${ }^{\text {Nestin }}$ mice showed less immobility regardless of saline or antidepressant treatment. ANOVA (GLM) found significant effects of genotype $\left(F_{(1,34)}=5.354, p=0.0269\right)$. Results are mean + SEM. ${ }^{*} p<0.05$.

We next assessed whether genetic activation of NPCs can provide antidepressive-like benefits in the CMS paradigm, an established rodent model that reflects some of the core behavioral symptoms of depression (Willner, 2005). We subjected cohorts of control and NF1 $1^{\text {Nestin }}$ mice to mild, unpredictable stress for 5 weeks starting at 8 months of age. Animals of either genotype were further subgrouped to receive saline, fluoxetine $(18 \mu \mathrm{g} / \mathrm{g})$ or imipramine $(20 \mu \mathrm{g} / \mathrm{g})$ in the last 3 weeks (Fig. 7A). At the end of the 5 week regimen, control stressed mice showed declining coat condition and less frequent self-grooming in the splash test compared with age-matched non-stressed mice (data not shown). Chronic exposure to fluoxetine or imipramine reversed these changes (Fig. $7 B, C ; n=6-7$ for each genotype, housing condition, and treatment). To the contrary, NF1 ${ }^{\text {Nestin }}$ mice were resistant to CMS, and treatment with either antidepressant did not lead to additional changes (Fig. $7 B, C$ ). Furthermore, CMS increased TST immobility in control mice (data not shown), which was reversed by chronic antidepressant (Fig. 7D). NF1 ${ }^{\text {Nestin }}$ mice, however were unaffected by CMS in the TST paradigm (Fig. 7D). Thus Nf1 deletion mimicked the effects of chronic antidepressants in ameliorating CMS-induced depression-like behaviors. Collectively, our results demonstrate that specific ablation of $\mathrm{NfI}$ in adult NPCs progressively activated hippocampal neurogenesis, and, by 8 months of age (6 months after Nf1 inactivation), produced antidepressive-like behaviors both at the basal state and under conditions of CMS.

\section{Discussion}

The continuous generation of new neurons by NPCs represents a unique form of structural plasticity in the adult nervous system. Investigating the molecular mechanisms that regulate the proliferation and differentiation of adult NPCs is critical for our understanding of the physiological functions of these cells, and could provide guidance to future therapeutics aimed at using this innate source of cellular regeneration. A recurring theme in research on neural stem and progenitor cells is the dependence of these cells on growth factors that relay signals by activating trans-membrane receptors including tyrosine kinases (RTKs). Neurofibromin is a RAS-GAP that regulates multiple RTK-downstream pathways. In the present study, we demonstrate that specific ablation of Nf1 in adult NPCs enhances proliferation and sensitizes them to subchronic antidepressants. In addition, lack of Nfl promotes the dendritic maturation of newly born neurons. These enhanced neurogenic responses coincide with our finding that $\mathrm{Nf1}$ deletion results in upregulation of the ERK pathway in NPCs and immature neurons, and strongly indicate that $\mathrm{Nfl}$ exerts cell-autonomous regulation on adult hippocampal neurogenesis. Interestingly, upregulation of ERK signaling was not observed in terminally differentiated $\mathrm{Nfl}^{-1-}$ cells (Fig. 3H). In addition, lack of Nf1 did not lead to noticeable increase in AKT activity in NPCs or their progeny (Fig. 3I). These results echo recent findings that, depending on cellular context, $\mathrm{Nfl}$ ablation can release inhibition of the ERK pathway, the PI3K pathway, or both (Hegedus et al., 2007; Luikart et al., 2008; Lush et al., 2008). It is likely that the presence of redundant GAPs contributes to the inhibition of RAS signaling. This is supported by recent findings that the neuronal-specific RAS-GAP protein SynGAP exerts similar developmental functions as $\mathrm{Nf1}$ in the formation of the rodent barrel cortex (Barnett et al., 2006; Lush et al., 2008). Further investigation of these regulatory machineries may provide insights into the nature of cell type-specific signal transduction. In light of the findings that $\mathrm{Nf1}$ ablation in adult NPCs did not lead to immediate increase in the number of dividing cells in 3-month-old NF1 ${ }^{\text {Nestin }}$ mice (Fig. 4F, G), but did enhance basal proliferation at 5 and 8 months of age (Fig. $6 A, B)$, it is possible that the gradual activation of the ERK pathway, as well as additional mechanisms on the molecular, cellular and circuitry levels, contributed to the regulation of basal proliferation and neurogenesis activity.

Cell type-specific ablation of Nf1, and the subsequent upregulation of the ERK pathway in selected cellular populations, provides us with the opportunity to analyze the impact of enhancing NPC activity on behavior. In the present study, we demonstrate that enhancing neurogenesis both facilitates and is sufficient to bring about the behavioral changes associated with chronic antidepressant administration in specific behavioral paradigms. Our results show that ablation of Nf1 in adult NPCs initiates a course of activation that first involves a phase of normal basal depression- and anxiety-like behaviors with enhanced sensitivity to antidepressants, followed by a later stage of improved basal depression- and anxiety-like behaviors. These behavioral changes correspond to the phase-activation of DG NPCs. In addition, long-term activation of adult NPCs rendered the NF1 ${ }^{\text {Nestin }}$ mice resistant to CMS in depression-like behavioral assays, mimicking the chronic effects of antidepressants. These results strongly suggest that enhancing adult neurogenesis, without manipulating existing neurons and glia, is sufficient to modulate depression- and anxiety-like behaviors. A recent study reported that genetic background may influence the mechanism by which chronic antidepressants produce behavioral improvements (Holick et al., 2008). In contrast to the present study and previous reports using the 129/SvEv and C57BL/6 strains (Santarelli et al., 2003; Encinas et al., 2006; Li et al., 2008; Wang et al., 2008), mice on the BALB/cJ background respond to chronic fluoxetine and desipramine independent of adult hippocampal neurogenesis or the serotonin $1 \mathrm{~A}$ receptor (Holick et al., 2008). These findings suggest diverse molecular and cellular mechanisms for the therapeutic effects of antidepressants, and underscore the likely possibility that the behavioral benefits of 
enhancing neurogenesis could be predetermined by genetic variations as well.

Newly born neurons in adult hippocampus represent a distinct population of cells with enhanced excitability and synaptic plasticity (Schmidt-Hieber et al., 2004; Ge et al., 2006, 2007). While a function for adult DG NPC-derived neurons remains to be directly demonstrated, it has been shown that ablation of adult NPCs in mice via X-irradiation interfered with normal learning and memory (Clelland et al., 2009; Kitamura et al., 2009). Recently, it was reported that preventing Bax-dependent apoptosis specifically in NPCs and their progeny led to expansion in the population of newly born neurons, and improved contextual fear-discrimination learning (Sahay et al., 2011), lending support to the notion that enhancing adult neurogenesis is sufficient to modulate cognition. The present study specifically focuses on investigating the impact of enhancing neurogenesis on mood, by assessing depression- and anxiety-like behaviors at 2, 6, and 9 months after genetic activation of NPCs. We note that although similar Nestin-CreER transgenic lines were used in these studies, the penetrance of tamoxifen-induced recombination in NPCs and newborn neurons was significantly different and may contribute to phenotypic differences: while Sahay et al. reported that recombination occurred in $57.5 \%$ of Dcx-positive cells (Sahay et al., 2011), our study demonstrates $100 \%$ of Dcx-positive cells recombined upon tamoxifen induction (Fig. 2). Consistent with previous findings (Li et al., 2008; Sahay et al., 2011), our results demonstrate that changes in depression- and anxiety-like behaviors on the basal level occur gradually, and are not significant at 1 month post-tamoxifen induction (Fig. 4). In response to subchronic antidepressant, the NF1 ${ }^{\text {Nestin }}$ mice demonstrated robust neurogenic and behavioral responses, suggesting $\mathrm{Nf1} 1^{-1-} \mathrm{NPCs}$ and immature neurons are sensitive to changes in the neurogenic niche elicited by antidepressant, and that increased production and maturation of newborn neurons leads to improvement in depression- and anxiety-related behaviors. Last, we showed that 8-month-old NF1 ${ }^{\text {Nestin }}$ mice displayed antidepressive-like behavioral changes similar to that of chronic antidepressants in the NSFT, TST, and FST, suggesting that sustained activation of NPCs could directly improve depression- and anxiety-like behaviors. Together, this work identifies novel functions for adult NPCs and provides a proof-of-principle analysis on the feasibility of regulating behavior via direct manipulation of adult neurogenesis.

\section{References}

Airan RD, Meltzer LA, Roy M, Gong Y, Chen H, Deisseroth K (2007) Highspeed imaging reveals neurophysiological links to behavior in an animal model of depression. Science 317:819-823.

Babu H, Cheung G, Kettenmann H, Palmer TD, Kempermann G (2007) Enriched monolayer precursor cell cultures from micro-dissected adult mouse dentate gyrus yield functional granule cell-like neurons. PLoS One 2:e388.

Barnett MW, Watson RF, Vitalis T, Porter K, Komiyama NH, Stoney PN, Gillingwater TH, Grant SG, Kind PC (2006) Synaptic Ras GTPase activating protein regulates pattern formation in the trigeminal system of mice. J Neurosci 26:1355-1365.

Brockschnieder D, Pechmann Y, Sonnenberg-Riethmacher E, Riethmacher D (2006) An improved mouse line for Cre-induced cell ablation due to diphtheria toxin A, expressed from the Rosa26 locus. Genesis 44:322-327.

Chen J, Kwon CH, Lin L, Li Y, Parada LF (2009) Inducible site-specific recombination in neural stem/progenitor cells. Genesis 47:122-131.

Clelland CD, Choi M, Romberg C, Clemenson GD Jr, Fragniere A, Tyers P, Jessberger S, Saksida LM, Barker RA, Gage FH, Bussey TJ (2009) A functional role for adult hippocampal neurogenesis in spatial pattern separation. Science 325:210-213.

Cui Y, Costa RM, Murphy GG, Elgersma Y, Zhu Y, Gutmann DH, Parada LF, Mody I, Silva AJ (2008) Neurofibromin regulation of ERK signaling modulates GABA release and learning. Cell 135:549-560.
Czéh B, Michaelis T, Watanabe T, Frahm J, de Biurrun G, van Kampen M, Bartolomucci A, Fuchs E (2001) Stress-induced changes in cerebral metabolites, hippocampal volume, and cell proliferation are prevented by antidepressant treatment with tianeptine. Proc Natl Acad Sci U S A 98:12796-12801.

Dasgupta B, Gutmann DH (2005) Neurofibromin regulates neural stem cell proliferation, survival, and astroglial differentiation in vitro and in vivo. J Neurosci 25:5584-5594.

David DJ, Samuels BA, Rainer Q, Wang JW, Marsteller D, Mendez I, Drew M, Craig DA, Guiard BP, Guilloux JP, Artymyshyn RP, Gardier AM, Gerald C, Antonijevic IA, Leonardo ED, Hen R (2009) Neurogenesisdependent and -independent effects of fluoxetine in an animal model of anxiety/depression. Neuron 62:479-493.

Encinas JM, Vaahtokari A, Enikolopov G (2006) Fluoxetine targets early progenitor cells in the adult brain. Proc Natl Acad Sci U S A 103:8233-8238.

Ge S, Goh EL, Sailor KA, Kitabatake Y, Ming GL, Song H (2006) GABA regulates synaptic integration of newly generated neurons in the adult brain. Nature 439:589-593.

Ge S, Yang CH, Hsu KS, Ming GL, Song H (2007) A critical period for enhanced synaptic plasticity in newly generated neurons of the adult brain. Neuron 54:559-566.

Gutmann DH, Collins FS (1993) The neurofibromatosis type 1 gene and its protein product, neurofibromin. Neuron 10:335-343.

Hegedus B, Dasgupta B, Shin JE, Emnett RJ, Hart-Mahon EK, Elghazi L, BernalMizrachiE, Gutmann DH (2007) Neurofibromatosis-1 regulates neuronal and glial cell differentiation from neuroglial progenitors in vivo by both cAMP- and Ras-dependent mechanisms. Cell Stem Cell 1:443-457.

Holick KA, Lee DC, Hen R, Dulawa SC (2008) Behavioral effects of chronic fluoxetine in BALB/CJ mice do not require adult hippocampal neurogenesis or the serotonin 1A receptor. Neuropsychopharmacology 33:406-417.

Imayoshi I, Sakamoto M, Ohtsuka T, Takao K, Miyakawa T, Yamaguchi M, Mori K, Ikeda T, Itohara S, Kageyama R (2008) Roles of continuous neurogenesis in the structural and functional integrity of the adult forebrain. Nat Neurosci 11:1153-1161.

Kempermann G, Kuhn HG, Gage FH (1997) More hippocampal neurons in adult mice living in an enriched environment. Nature 386:493-495.

Kitamura T, Saitoh Y, Takashima N, Murayama A, Niibori Y, Ageta H, Sekiguchi M, Sugiyama H, Inokuchi K (2009) Adult neurogenesis modulates the hippocampus-dependent period of associative fear memory. Cell 139:814-827.

Klesse LJ, Parada LF (1998) p21 ras and phosphatidylinositol-3 kinase are required for survival of wild-type and NF1 mutant sensory neurons. J Neurosci 18:10420-10428.

Krishnan V, Han MH, Graham DL, Berton O, Renthal W, Russo SJ, Laplant Q, Graham A, Lutter M, Lagace DC, Ghose S, Reister R, Tannous P, Green TA, Neve RL, Chakravarty S, Kumar A, Eisch AJ, Self DW, Lee FS, et al. (2007) Molecular adaptations underlying susceptibility and resistance to social defeat in brain reward regions. Cell 131:391-404.

Lee DY, Yeh TH, Emnett RJ, White CR, Gutmann DH (2010) Neurofibromatosis-1 regulates neuroglial progenitor proliferation and glial differentiation in a brain region-specific manner. Genes Dev 24:2317-2329.

Li Y, Luikart BW, Birnbaum S, Chen J, Kwon CH, Kernie SG, Bassel-Duby R, Parada LF (2008) TrkB regulates hippocampal neurogenesis and governs sensitivity to antidepressive treatment. Neuron 59:399-412.

Luikart BW, Zhang W, Wayman GA, Kwon CH, Westbrook GL, Parada LF (2008) Neurotrophin-dependent dendritic filopodial motility: a convergence on PI3K signaling. J Neurosci 28:7006-7012.

Lush ME, Li Y, Kwon CH, Chen J, Parada LF (2008) Neurofibromin is required for barrel formation in the mouse somatosensory cortex. J Neurosci 28:1580-1587.

Malberg JE, Eisch AJ, Nestler EJ, Duman RS (2000) Chronic antidepressant treatment increases neurogenesis in adult rat hippocampus. J Neurosci 20:9104-9110.

Monje ML, Toda H, Palmer TD (2003) Inflammatory blockade restores adult hippocampal neurogenesis. Science 302:1760-1765.

Nibuya M, Morinobu S, Duman RS (1995) Regulation of BDNF and trkB mRNA in rat brain by chronic electroconvulsive seizure and antidepressant drug treatments. J Neurosci 15:7539-7547.

Plümpe T, Ehninger D, Steiner B, Klempin F, Jessberger S, Brandt M, Römer B, Rodriguez GR, Kronenberg G, Kempermann G (2006) Variability of doublecortin-associated dendrite maturation in adult hippocampal neurogenesis is independent of the regulation of precursor cell proliferation. BMC Neurosci 7:77. 
Sahay A, Scobie KN, Hill AS, O'Carroll CM, Kheirbek MA, Burghardt NS, Fenton AA, Dranovsky A, Hen R (2011) Increasing adult hippocampal neurogenesis is sufficient to improve pattern separation. Nature 472:466-470.

Santarelli L, Saxe M, Gross C, Surget A, Battaglia F, Dulawa S, Weisstaub N, Lee J, Duman R, Arancio O, Belzung C, Hen R (2003) Requirement of hippocampal neurogenesis for the behavioral effects of antidepressants. Science 301:805-809.

Saxe MD, Battaglia F, Wang JW, Malleret G, David DJ, Monckton JE, Garcia AD, Sofroniew MV, Kandel ER, Santarelli L, Hen R, Drew MR (2006) Ablation of hippocampal neurogenesis impairs contextual fear conditioning and synaptic plasticity in the dentate gyrus. Proc Natl Acad Sci U S A 103:17501-17506.

Schmidt-Hieber C, Jonas P, Bischofberger J (2004) Enhanced synaptic plasticity in newly generated granule cells of the adult hippocampus. Nature 429:184-187.

Scott BW, Wojtowicz JM, Burnham WM (2000) Neurogenesis in the dentate gyrus of the rat following electroconvulsive shock seizures. Exp Neurol 165:231-236.

Soriano P (1999) Generalized lacZ expression with the ROSA26 Cre reporter strain. Nat Genet 21:70-71.

Stranahan AM, Khalil D, Gould E (2006) Social isolation delays the positive effects of running on adult neurogenesis. Nat Neurosci 9:526-533.
Vogel KS, Brannan CI, Jenkins NA, Copeland NG, Parada LF (1995) Loss of neurofibromin results in neurotrophin-independent survival of embryonic sensory and sympathetic neurons. Cell 82:733-742.

Wang JW, David DJ, Monckton JE, Battaglia F, Hen R (2008) Chronic fluoxetine stimulates maturation and synaptic plasticity of adult-born hippocampal granule cells. J Neurosci 28:1374-1384.

Warner-Schmidt JL, Duman RS (2007) VEGF is an essential mediator of the neurogenic and behavioral actions of antidepressants. Proc Natl Acad Sci U S A 104:4647-4652.

Willner P (2005) Chronic mild stress (CMS) revisited: consistency and behavioural-neurobiological concordance in the effects of CMS. Neuropsychobiology 52:90-110.

Zhang CL, Zou Y, He W, Gage FH, Evans RM (2008) A role for adult TLX-positive neural stem cells in learning and behaviour. Nature 451:1004-1007.

Zhou J, Blundell J, Ogawa S, Kwon CH, Zhang W, Sinton C, Powell CM, Parada LF (2009) Pharmacological inhibition of mTORC1 suppresses anatomical, cellular, and behavioral abnormalities in neural-specific Pten knock-out mice. J Neurosci 29:1773-1783.

Zhu Y, Romero MI, Ghosh P, Ye Z, Charnay P, Rushing EJ, Marth JD, Parada LF (2001) Ablation of NF1 function in neurons induces abnormal development of cerebral cortex and reactive gliosis in the brain. Genes Dev 15:859-876. 